\title{
Review Article \\ Electronic Properties of Antiperovskite Materials from State-of-the-Art Density Functional Theory
}

\author{
M. Bilal, ${ }^{1,2}$ S. Jalali-Asadabadi, ${ }^{3}$ Rashid Ahmad, ${ }^{4}$ and Iftikhar Ahmad ${ }^{1,2}$ \\ ${ }^{1}$ Center for Computational Materials Science, University of Malakand, Chakdara, Pakistan \\ ${ }^{2}$ Department of Physics, University of Malakand, Chakdara, Pakistan \\ ${ }^{3}$ Department of Physics, Faculty of Science, University of Isfahan (UI), Hezar Gerib Avenue, Isfahan 81746-73441, Iran \\ ${ }^{4}$ Department of Chemistry, University of Malakand, Chakdara, Pakistan
}

Correspondence should be addressed to Iftikhar Ahmad; ahma5532@gmail.com

Received 1 January 2015; Revised 2 February 2015; Accepted 2 February 2015

Academic Editor: Theocharis C. Stamatatos

Copyright (C) 2015 M. Bilal et al. This is an open access article distributed under the Creative Commons Attribution License, which permits unrestricted use, distribution, and reproduction in any medium, provided the original work is properly cited.

\begin{abstract}
We present a review on the research developments on the theoretical electronic properties of the antiperovskite materials. The antiperovskite materials have perovskite type structure with the positions of cations and anions interchanged. The electronic structures are used to explain different physical properties of materials; therefore it is crucial to understand band structures and densities of states of materials for their effective use in technology. The theoretical results of the electronic structure of antiperovskites were discussed and compared with the available experimental results to measure the accuracy of the research done so far on these materials. The important physical properties of these compounds like magnetic properties and superconductivity are also highlighted. Nevertheless the thermoelectric properties of these materials are still unexplored except for a few reports which suggest that antiperovskite materials may be potential candidates for thermoelectric generators.
\end{abstract}

\section{Introduction}

Many materials adopt perovskite type structure with formula $\mathrm{ABX}_{3}$, where $\mathrm{A}$ and $\mathrm{B}$ are cations while $\mathrm{X}$ is anion. The $\mathrm{X}$ atoms make twelvefold symmetry being at the center of the edges of the unit cell, $\mathrm{A}$ atom at the center and $\mathrm{B}$ atoms at the corners of the unit cell. Generally, $\mathrm{X}$ atoms make octahedral coordination being at the face centers of the unit cell, $\mathrm{A}$ atoms at the corners and $\mathrm{B}$ atom at the center [1]. The first perovskite material $\mathrm{CaTiO}_{3}$ was discovered by Gustav Rose [2] and he named it after a Russian mineralogist Lev Perovski. Perovskites have different types like simple perovskites $\left(\mathrm{KMnF}_{3}\right.$ [3] and $\left.\mathrm{SrTiO}_{3}[4]\right)$, antiperovskites $\left(\mathrm{SbNCa}_{3}\right.$ and $\left.\mathrm{BiNCa}_{3}[1]\right)$, inverse perovskites $\left(\left(\mathrm{Eu}_{3} \mathrm{O}\right) \mathrm{In}\right.$ and $\left.\left(\mathrm{Eu}_{3} \mathrm{O}\right) \mathrm{Sn}[5]\right)$, double perovskites $\left(\mathrm{SrLaVMoO}_{6}[6]\right)$, and double antiperovskites $\left(\mathrm{Na}_{6} \mathrm{FCl}\left(\mathrm{SO}_{4}\right)_{2}[7]\right)$ depending on composition and chemistry of the constituent elements of the material. Different structures are found in all these types like cubic [8], orthorhombic [9], tetragonal [10], rhombohedral [11], and hexagonal [12].

Antiperovskite materials are inorganic compounds, having perovskite type structure with the positions of anions and cations interchanged [13]. Figure 1 presents the simplest cubic antiperovskites structure, with space group Pm3m (221) [14]. For having utility in different industrial applications, antiperovskites have attracted significant attention of the researchers in the past decade [15]. Wide range of band gaps in these materials is one of the important reasons for their industrial utility $[16,17]$. Antiperovskites have immense potential to solve energy crisis as these materials have good thermoelectric (TE) properties [18]. In thermoelectrics, waste heat is directly converted to electrical energy. Researchers seek suitable materials for thermoelectric generators to achieve high efficiency. Good thermoelectric materials typically have band gaps large enough to have a large Seebeck coefficient, but small enough to have a sufficiently high electrical conductivity [19].

The family of antiperovskite materials has all kind of compounds including metals, semiconductors, insulators, and superconductors which make them applicable in various technologies. In batteries, solids having super ionic conductance are considered better than the organic liquid electrolytes [20] and hence lithium-based antiperovskites can 


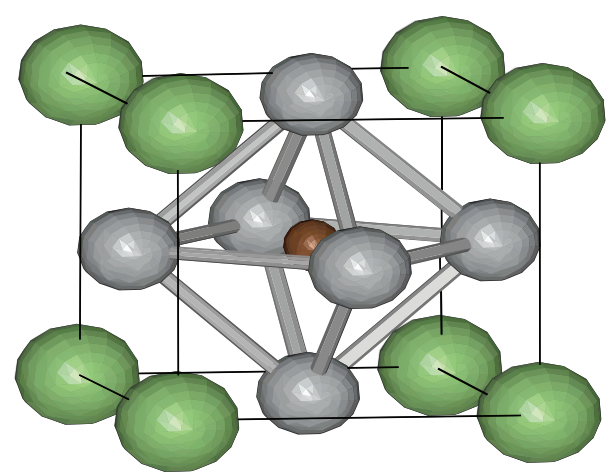

FIGURE 1: Unit cell of cubic antiperovskite with space group Pm3m (221), where green atoms at corner and brown atom at body center are anions while face centered grey atoms are cations. Figure reproduced with permission from Sieberer et al. [14].

be used as solid electrolytes in batteries [21]. Furthermore, these materials have interesting physical properties like giant magnetoresistance (GMR) [22], nearly zero temperature coefficients of resistivity [23], and magnetostriction [24]. These properties make antiperovskites very useful in industrial applications as GMR, used in magnetic field sensors, which are used to read data in hard disk drives, biosensors, microelectromechanical systems (MEMS), and other devices. Similarly, zero temperature coefficient of resistivity makes antiperovskites suitable materials in all weathers. Along with these applications, antiperovskites also show excellent mechanical properties [25-27], which make their possible utility in automobile and space technology, as we need materials with lightweight on one hand and large mechanical strength on the other hand in this industry. Superconductivity is also found in antiperovskites. In 2001, first antiperovskite material $\mathrm{MgCNi}_{3}$ was reported to have superconductivity below $8 \mathrm{~K}$ temperature [28]. This finding opened new avenues in research, regarding antiperovskite family. Literature reveals that other materials like $\mathrm{CdCNi}_{3}$ and $\mathrm{ZnNNi}_{3}$ also show superconductivity [29]. Furthermore, magnetism is one of the most important properties found in antiperovskites with diverse magnetic structures and different transition temperatures $[25,30]$. Due to strong magnetic effects, these materials are very attractive for applications in memory devices and sensors and appropriate for spintronics. Moreover, the presence of small band gaps in many antiperovskites makes them good candidates for optical devices. The available literature on these compounds shows that researchers around the globe are taking keen interest in the optical properties of antiperovskites [17, 31, 32].

Different physical properties like thermoelectric, optical, magnetic, and mechanical properties are strongly dependent upon the electronic properties of a material. Small variation in the electronic structure causes large changes in these properties. Therefore, it is very important to have a deep understanding of band structures and density of states of materials for their effective use in optical, memory storage, and thermoelectric devices. The aim of this review article is to present a comprehensive discussion on the theoretical studies of the electronic properties of antiperovskite type materials.
This work presents deep insight into the development of research on the subject and we hope that this review will benefit the researchers working in this field.

\section{Group II-A Based Antiperovskites Materials}

Group II-A elements are very important due to their diverse applications in electronics [33], mechanics [34], and military [35]. These elements have two electrons in their outermost shell and easily loose them to make ionic bonds in general. There are many antiperovskite materials which have a group II-A element at face center of the unit cell making octahedral coordination. Chern et al. synthesized calcium based antiperovskite material $\mathrm{BiNCa}_{3}$, by mixing and pressing powders of $\mathrm{Ca}_{3} \mathrm{~N}_{2}$ and $\mathrm{Bi}$ into a pellet and afterwards heating the pellet at $1000^{\circ} \mathrm{C}$ in flowing, dry $\mathrm{N}_{2}$ gas [1]. The authors substituted $\mathrm{Bi}$ with other trivalent elements, $\mathrm{P}, \mathrm{As}, \mathrm{Sb}, \mathrm{Ge}, \mathrm{Sn}$, and $\mathrm{Pb}$, and found the same result as expected. The authors report that all these materials are found in cubic structure except $\mathrm{PNCa}_{3}$ and $\mathrm{AsNCa}_{3}$ which have distorted orthorhombic structure due to small $\mathrm{P}^{-3}$ and $\mathrm{As}^{-3}$ atomic size. Resistivity measurements show that $\mathrm{PbNCa}_{3}, \mathrm{SnNCa}_{3}$, and $\mathrm{GeNCa}_{3}$ materials are metallic in nature, $\mathrm{BiNCa}_{3}$ and $\mathrm{SbNCa}_{3}$ are semiconductors with small band gaps, while $\mathrm{AsNCa}_{3}$ and $\mathrm{PNCa}_{3}$ show insulating behavior with structural phase transitions.

Consequently, different researchers theoretically investigated the electronic properties like band structures and densities of states of these materials for the deep understanding of their relevant behavior in other physical properties. Papaconstantopoulos and Pickett [36] studied the electronic properties of $\mathrm{BiNCa}_{3}$ and $\mathrm{PbNCa}_{3}$ using local density approximation (LDA) which generally underestimates band gaps. The authors show that $\mathrm{BiNCa}_{3}$ is a narrow band gap semiconductor and $\mathrm{PbNCa}_{3}$ is a metallic material confirming the experimental results as presented in Figures $2(\mathrm{a})$ and $2(\mathrm{~b}) . \mathrm{Pb}$ has one electron less than $\mathrm{Bi}$ and $\mathrm{BiNCa}_{3}$ has a very small band gap; therefore $\mathrm{PbNCa}_{3}$ was expected to be a metal. The valences of the constituent elements in $\mathrm{BiNCa}_{3}$ give an ionic picture of the compound; however, authors argue that at the same time strong covalent mixing is present due to $\mathrm{p}$-states of $\mathrm{Bi}$ and $\mathrm{N}$.

Vansant et al. [37] studied pressure dependent structural and electronic properties of $\mathrm{PNCa}_{3}, \mathrm{AsNCa}_{3}$, and $\mathrm{BiNCa}_{3}$ using LDA. The atomic positions of the orthorhombic $\mathrm{AsNCa}_{3}$ are presented in Table 1, reproduced from [38]. Vansant et al. verified that at ambient temperature and pressures $\mathrm{AsNCa}_{3}$ and $\mathrm{PNCa}_{3}$ adopt orthorhombic structure with Pbnm space group while $\mathrm{BiNCa}_{3}$ is a simple cube with $\mathrm{Pm} 3 \mathrm{~m}$ space group. It is also worth noting that the orthorhombic $\mathrm{AsNCa}_{3}$ structure turns out to be more stable than the cubic SC5 structure with increasing pressure whereas band gap decreases with pressure for this material. At $59 \mathrm{GPa}$ pressure, $\mathrm{AsNCa}_{3}$ shows a phase transition to cubic SC15 with 15 atoms per unit cell.

Moakafi et al. studied elastic, electronic, and optical properties of cubic antiperovskites $\mathrm{SbNCa}_{3}$ and $\mathrm{BiNCa}_{3}$ [31]. The authors used three different potentials, that is, LDA, generalized gradient approximation (GGA), and Engel Vosko (EV-GGA), to investigate the electronic properties of these 


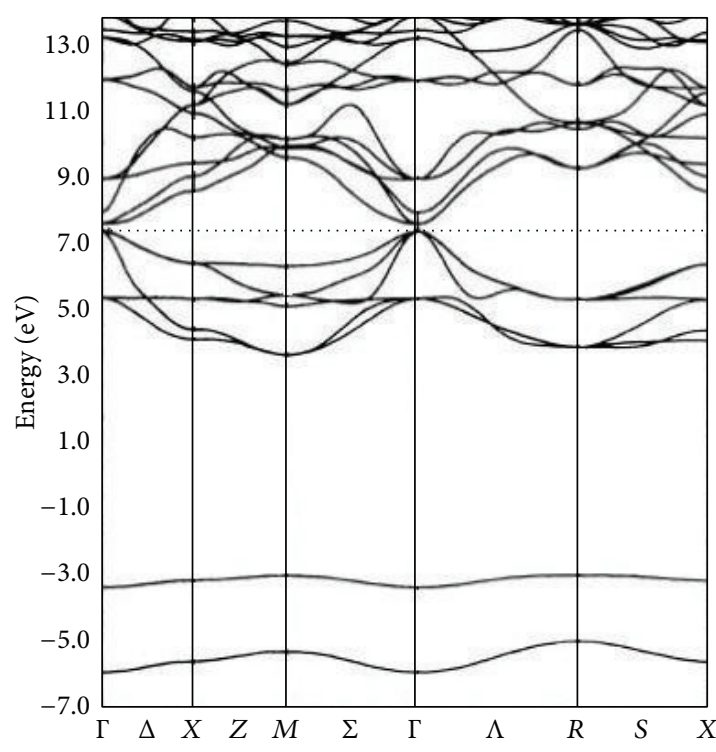

(a)

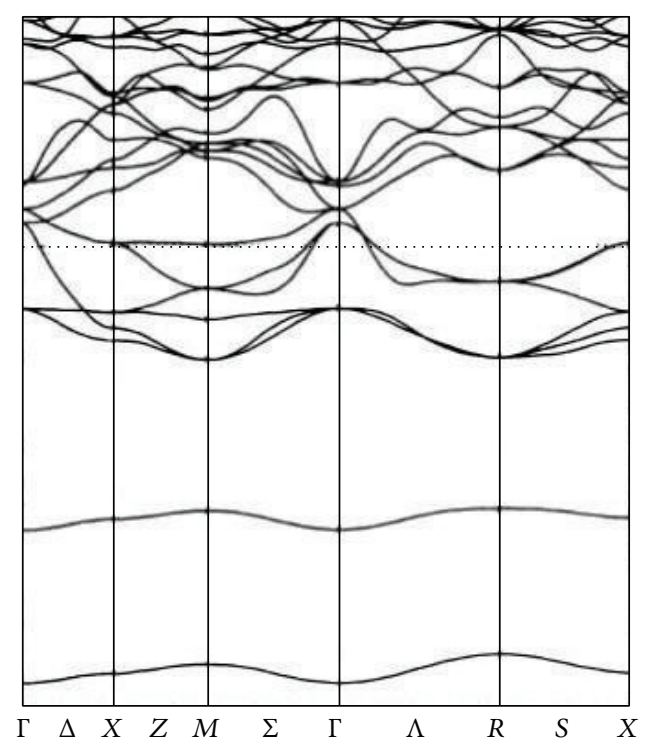

(b)

Figure 2: Band structures of (a) $\mathrm{BiNCa}_{3}$ and (b) $\mathrm{PbNCa}_{3}$ reproduced with permission from [36].

TABLE 1: Atomic positions of orthorhombic $\mathrm{AsNCa}_{3}$ with space group Pbnm reproduced with permission of [38].

\begin{tabular}{lcc}
\hline $\mathrm{Ca}(1)$ & $\pm\left(3 / 4-\Delta_{1}, 1 / 4+\Delta_{2}, \delta\right) ;$ & $\pm\left(3 / 4-\Delta_{1}, 1 / 4+\Delta_{2}, 1 / 2-\delta\right) ;$ \\
& $\pm\left(3 / 4+\Delta_{1}, 3 / 4+\Delta_{2}, \delta\right) ;$ & $\pm\left(3 / 4+\Delta_{1}, 3 / 4+\Delta_{2}, 1 / 2-\delta\right) ;$ \\
\hline $\mathrm{Ca}(2)$ & $\pm\left(\gamma_{1}, 1 / 2-\gamma_{2}, 1 / 4\right) ;$ & $\pm\left(1 / 2-\gamma_{1},-\gamma_{2}, 1 / 4\right) ;$ \\
\hline $\mathrm{N}$ & $1 / 2,0,0 ;$ & $1 / 2,0,1 / 2 ;$ \\
\hline $\mathrm{As}$ & $0,1 / 2,0 ;$ & $0,1 / 2,1 / 2 ;$ \\
\hline
\end{tabular}

materials, and obtained band gaps of 0.65 and $0.36 \mathrm{eV}$ for $\mathrm{SbNCa}_{3}$ and $\mathrm{BiNCa}_{3}$, respectively. Their work shows that EV-GGA is a better technique than LDA and GGA for the calculation of the band structures of these materials. However, the authors got wider band gaps using EV-GGA but the valance bands crossing the Fermi level show metallic behavior of these materials which is in contradiction to the experimental results.

This work was revisited by Bilal et al. [39] and they presented a comprehensive study on the band profiles and structural and optical properties of $\mathrm{SbNCa}_{3}$ and $\mathrm{BiNCa}_{3}$ antiperovskites. Along with LDA, GGA, and EV-GGA potentials, they also used modified Becke-Johnson (mBJ) potential to calculate accurate electronic properties of these materials. They achieved direct band gap values of 1.1 and $1.09 \mathrm{eV}$ for $\mathrm{SbNCa}_{3}$ and $\mathrm{BiNCa}_{3}$, respectively, from $\mathrm{mBJ}$ potential. The band structures calculated by all potentials mentioned above are presented in Figure 3. It is clear from the figure that both materials show semiconducting behavior, verifying the experimental results with $\mathrm{mBJ}$, giving the largest values of band gaps.

Chi et al. synthesized magnesium-based antiperovskites, $\mathrm{AsNMg}_{3}$ and $\mathrm{SbNMg}_{3}$, by the reaction of pnictogen with $\mathrm{Mg}_{3} \mathrm{~N}_{2}$ at $800^{\circ} \mathrm{C}$ and investigated structural, transport, and magnetic properties of these materials [40]. The authors report cubic structures for both materials with no distortion. Both materials show ionic bonding with negative 3 valence of $\mathrm{As}, \mathrm{Sb}$, and $\mathrm{N}$. The authors classified both materials semiconductors based on resistivity data. Paramagnetic behavior is observed according to low-field magnetization data obtained at $50 \mathrm{G}$.

Shein and Ivanovskii studied the electronic band structure and chemical bonding in $\mathrm{AsNMg}_{3}$ and $\mathrm{SbNMg}_{3}$ antiperovskite materials using GGA [41]. Figures 4(a) and 4(b) present band structures of the materials achieved by the authors. Both materials show narrow band gap ionic semiconducting behavior. $\mathrm{AsNMg}_{3}$ has direct band gap while $\mathrm{SbNMg}_{3}$ shows indirect band gap nature.

Okoye discussed structural, electronic, and optical properties of $\mathrm{AsNMg}_{3}$ and $\mathrm{SbNMg}_{3}$ using full potential augmented plane waves plus local orbital (APW + lo) method [17]. GGA scheme was used for the electronic and optical properties of these materials. This was the first study on the optical properties of these materials. In this work the author verified the previous results [17] and confirmed that both materials have narrow band gaps with $\mathrm{AsNMg}_{3}$ possessing direct band gap whereas $\mathrm{SbNMg}_{3}$ reveals indirect band gap nature. The author argues that as DFT usually underestimates band gaps, therefore the calculated positions of the optical spectrum may be smaller than the experimental values. 

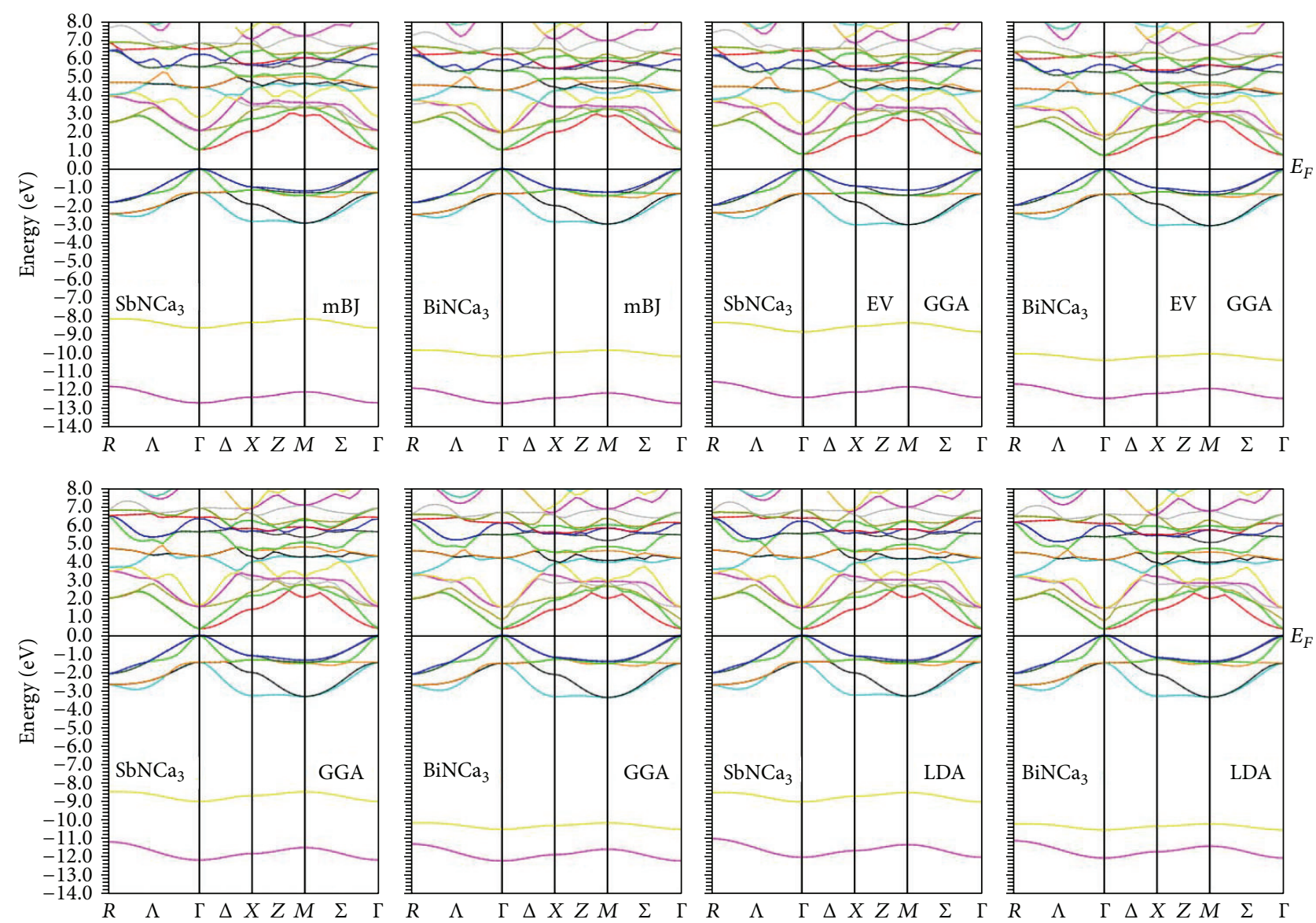

Figure 3: Band structures of $\mathrm{SbNCa}_{3}$ and $\mathrm{BiNCa}_{3}$ from LDA, GGA, EV-GGA, and $\mathrm{mBJ}$ reproduced from our previous work [39].

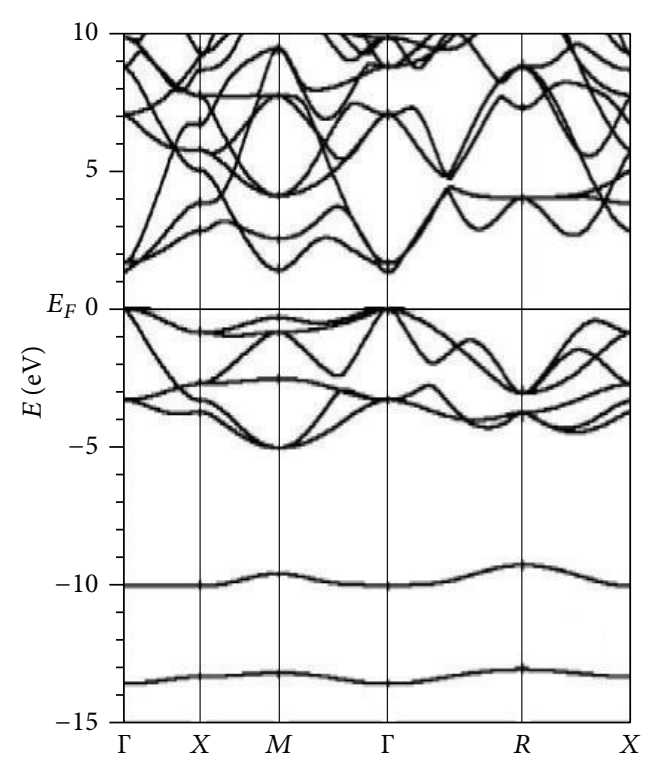

(a)

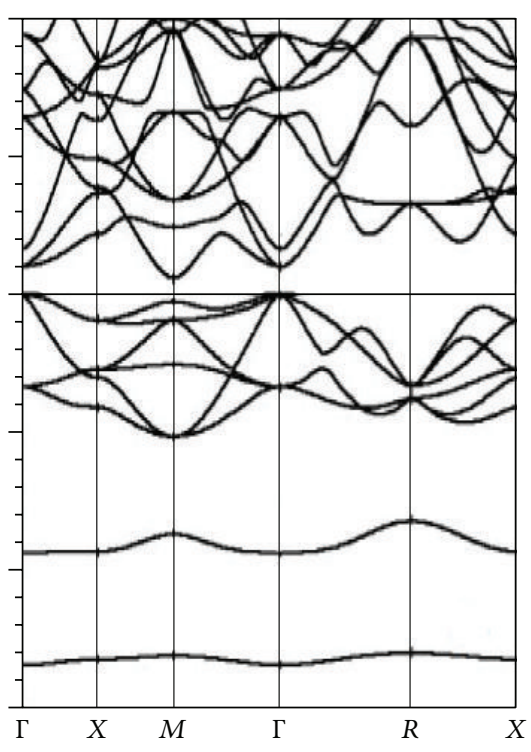

(b)

FIgURE 4: Band structures of (a) $\mathrm{AsNMg}_{3}$ and (b) $\mathrm{SbNMg}_{3}$ reproduced with permission from [41]. 


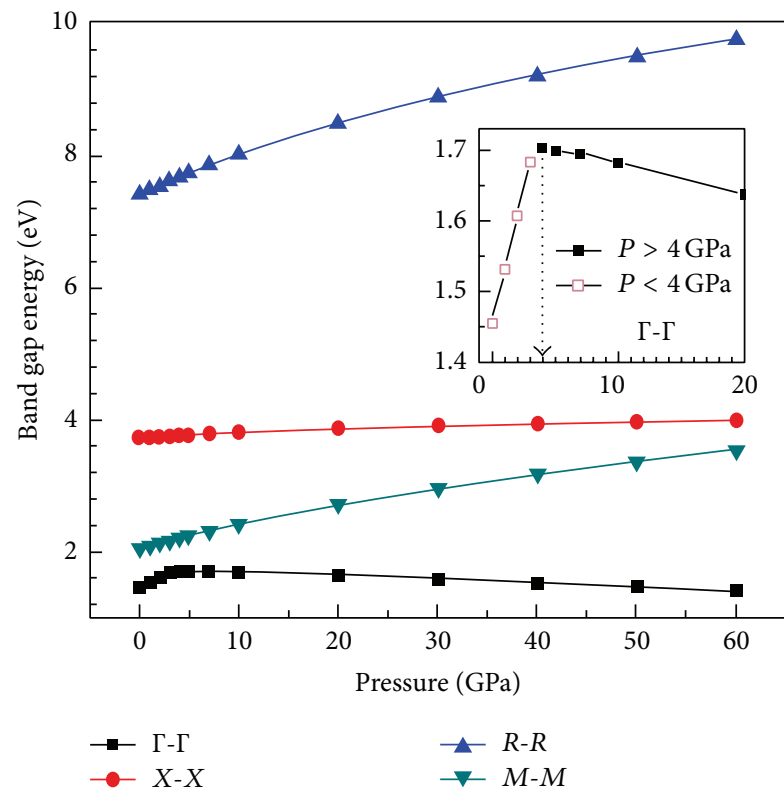

(a)

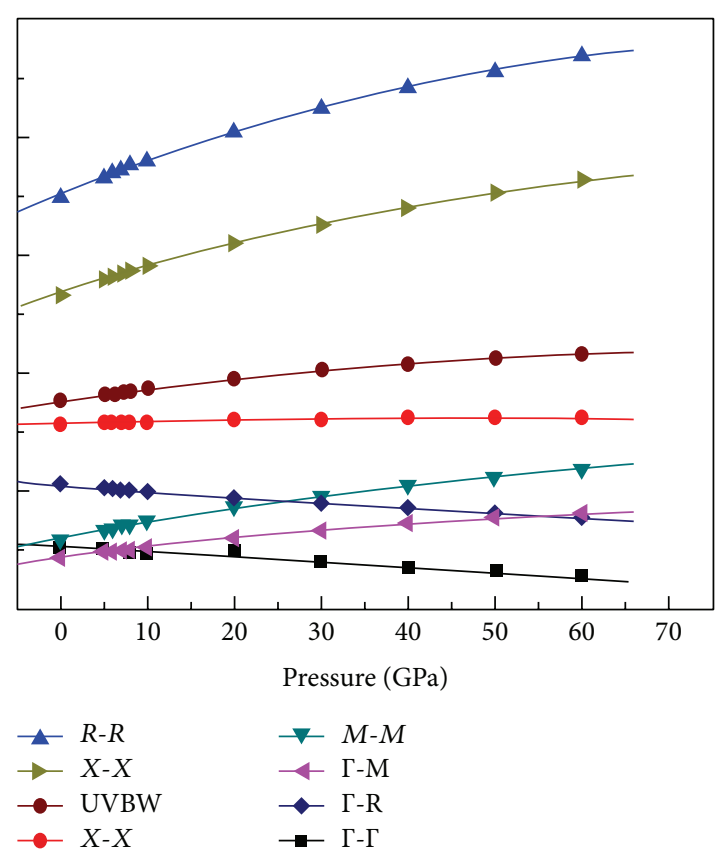

(b)

Figure 5: Direct and indirect band gap energies and upper valence bandwidth versus pressure for (a) $\mathrm{AsNMg}_{3}$ and (b) $\mathrm{SbNMg}_{3}$ reproduced with permission from [42] and [16], respectively.

The imaginary part of dielectric function, presented in their work, also confirms the semiconducting behavior of the materials.

Bouhemadou and coauthors investigated the structural electronic, elastic, and optical properties of $\mathrm{AsNMg}_{3}$ [42] and $\mathrm{SbNMg}_{3}$ [16] materials using pseudopotential plane waves method (PP-PW) within the generalized gradient approximation (GGA). For $\mathrm{AsNMg}_{3}$ the fundamental direct band gap initially increases up to $4 \mathrm{GPa}$ and then decreases as a function of pressure, concurrently retaining its direct band gap nature in entire pressure range applied, while $\mathrm{SbNMg}_{3}$ shows transition from fundamental indirect band gap to direct band gap nature as pressure reaches $6.85 \mathrm{GPa}$ as shown in Figures 5(a) and 5(b). These were the first theoretical studies on elastic properties of these materials; consequently Belaroussi et al. [43] studied the structural and elastic properties of $\mathrm{SbNMg}_{3}$ theoretically and compared their studies with this work.

Amara et al. investigated the structural, elastic, and electronic properties of $\mathrm{PNMg}_{3}, \mathrm{AsNMg}_{3}, \mathrm{SbNMg}_{3}$, and $\mathrm{BiNMg}_{3}$ using the full-potential augmented plane waves plus local orbital (FP-LAPW + lo) within the GGA, while treating the exchange and correlation effects by the Tran-Blaha mBJ potential for the band structure, density of states, and charge density to achieve better results [44]. This is the first study on $\mathrm{PNMg}_{3}$ and $\mathrm{BiNMg}_{3}$ antiperovskite materials. All materials show semiconducting behavior. Table 2 reproduced from [44] shows that $\mathrm{PNMg}_{3}$ and $\mathrm{AsNMg}_{3}$ are direct band gap materials while $\mathrm{SbNMg}_{3}$ and $\mathrm{BiNMg}_{3}$ are indirect band gap materials. The authors achieved largest values of band gaps as compared to previous studies due to the use of $\mathrm{mBJ}$ potential. The elastic
TABLE 2: Band gap type and energy gap for $\mathrm{XNMg}_{3}(\mathrm{X}=\mathrm{P}, \mathrm{As}, \mathrm{Sb}$, and $\mathrm{Bi}$ ), reproduced with permission from [44].

\begin{tabular}{lcc}
\hline Compound & Band gap type & Energy gap (eV) \\
\hline $\mathrm{PNMg}_{3}$ & Direct band gap & 2.60 \\
$\mathrm{AsNMg}_{3}$ & $\begin{array}{c}\text { Direct band gap } \\
\mathrm{SbNMg}_{3}\end{array}$ & $\begin{array}{c}\text { Indirect band } \\
\text { gap }\end{array}$ \\
$\mathrm{BiNMg}_{3}$ & $\begin{array}{c}\text { Indirect band } \\
\text { gap }\end{array}$ & 1.48 \\
&
\end{tabular}

properties show that $\mathrm{PNMg}_{3}$ is the hardest while $\mathrm{BiNMg}_{3}$ is the softest material out of all. Increase in covalent nature is observed in these materials in moving from $\mathrm{BiNMg}_{3}$ to $\mathrm{PNMg}_{3}$.

Beznosikov worked on nitrides with antiperovskites structure and analytically calculated lattice parameters of $\mathrm{AsNSr}_{3}, \mathrm{SbNSr}_{3}$, and $\mathrm{BiNSr}_{3}$ materials [45]. Gäbler et al. synthesized $\mathrm{SbNX}_{3}$ and $\mathrm{BiNX}_{3}(\mathrm{X}=\mathrm{Sr}$ and $\mathrm{Ba})$ antiperovskite materials in 2004 for the first time [46]. The compositions were derived from chemical analyses and supported by Rietveld refinements based on powder X-ray diffraction patterns. $\mathrm{SbNSr}_{3}$ and $\mathrm{BiNSr}_{3}$ are found in cubic $(\mathrm{Pm} 3 \mathrm{~m})$ while $\mathrm{SbNBa}_{3}$ and $\mathrm{BiNBa}_{3}$ are found in hexagonal $(\mathrm{P} 63 / \mathrm{mmc})$ structure. The authors reported magnetic, electronic, optical, and bonding properties of these materials. The electrical resistivity studies show that these materials are semiconductors. The optical band gaps of $1.15 \mathrm{eV}$ for $\mathrm{SbNSr}_{3}$ and $0.89 \mathrm{eV}$ for $\mathrm{BiNSr}_{3}$ are measured by diffuse reflectivity method. The authors also calculated the electronic band gaps 
TABLE 3: Experimental and theoretical band gap values (in eV) of antiperovskite materials.

\begin{tabular}{|c|c|c|c|c|c|}
\hline Material & $\begin{array}{l}\text { Experimental band } \\
\text { gap }\end{array}$ & LDA & GGA & EVGGA & $\mathrm{mBJ}$ \\
\hline $\mathrm{SbNCa}_{3}$ & Semiconductor [1] & 0.13 [31], 0.4 [39], & 0.33 [31], 0.42 [39], & $\begin{array}{c}0.65[31], 0.84 \\
\text { [39], }\end{array}$ & $1.1[39]$ \\
\hline $\mathrm{BiNCa}_{3}$ & Semiconductor [1] & $\begin{array}{c}0.1[36], 0.28[37], 0.11 \\
{[31], 0.38 \text { [39], }}\end{array}$ & 0.08 [31], 0.4 [39], & $\begin{array}{c}0.36[31], 0.8 \\
{[39],}\end{array}$ & 1.09 [39], \\
\hline $\mathrm{AsNCa}_{3}$ & Insulator [1] & $0.87[37]$ & & & \\
\hline $\mathrm{PNCa}_{3}$ & Insulator [1] & $1.1[37]$ & & & \\
\hline $\mathrm{AsNMg}_{3}$ & $\begin{array}{l}\text { Semiconductor } \\
{[40]}\end{array}$ & & $\begin{array}{c}1.332[17,41], \\
1.455[42]\end{array}$ & & $2.41[44]$ \\
\hline $\mathrm{SbNMg}_{3}$ & $\begin{array}{l}\text { Semiconductor } \\
{[40]}\end{array}$ & & $\begin{array}{c}0.623[41], 0.866[16] \\
0.726[17]\end{array}$ & & $1.48[44]$, \\
\hline $\mathrm{PNMg}_{3}$ & & & & & $2.6[44]$ \\
\hline $\mathrm{BiNMg}_{3}$ & & & & & $1.42[44]$, \\
\hline $\mathrm{SbNSr}_{3}$ & $\begin{array}{l}\text { Semiconductor } \\
1.15[46]\end{array}$ & & $0.31[47]$ & $0.55[32]$ & \\
\hline $\mathrm{BiNSr}_{3}$ & $\begin{array}{l}\text { Semiconductor } \\
0.89[46]\end{array}$ & & $0.26[47]$ & $0.36[32]$ & \\
\hline $\mathrm{AsNSr}_{3}$ & & & $0.49[47]$ & $0.84[32]$ & \\
\hline $\mathrm{SbNBa}_{3}$ & $\begin{array}{l}\text { Semiconductor } \\
{[46]}\end{array}$ & & $\begin{array}{c}0.529[48], \text { metallic } \\
{[50]}\end{array}$ & & \\
\hline $\mathrm{BiNBa}_{3}$ & $\begin{array}{c}\text { Semiconductor } \\
{[46]}\end{array}$ & & $\begin{array}{c}0.529[48], \text { metallic } \\
{[50]}\end{array}$ & & \\
\hline
\end{tabular}

by DFT-based employing LDA and received small values arguing that LDA severely underestimated band gaps of crystalline materials. The susceptibility measurements show that the materials are diamagnetic.

Haddadi et al. [47] worked on the structural, elastic, and electronic properties of $\mathrm{ANSr}_{3}(\mathrm{~A}=\mathrm{As}, \mathrm{Sb}$, and $\mathrm{Bi})$ materials in 2009 using CASTEP code, in which the plane waves pseudopotential total energy method is employed. The authors used theoretical lattice parameters from [45] instead of using experimental lattice parameters from [46] for optimization. Surprisingly, the lattice parameters achieved by the authors exactly match the experimental data. The band gap values of $0.49,0.31$, and $0.26 \mathrm{eV}$ are calculated for $\mathrm{AsNSr}_{3}, \mathrm{SbNSr}_{3}$, and $\mathrm{BiNSr}_{3}$ materials, respectively, which are underestimated from their experimental optical band gaps [46] (see Table 3).

Hichour et al., in 2010, studied pressure dependent elastic, electronic, and optical properties of $\mathrm{ANSr}_{3}(\mathrm{~A}=\mathrm{As}, \mathrm{Sb}$, and $\mathrm{Bi}$ ) antiperovskites materials [32]. The authors used EVGGA potential to improve the band gaps of these materials and achieved 0.84, 0.55, and $0.36 \mathrm{eV}$ for $\mathrm{AsNSr}_{3}, \mathrm{SbNSr}_{3}$, and $\mathrm{BiNSr}_{3}$, respectively. The band gap values decrease for all materials as pressure increases. The charge density plots show that these materials have mixed covalent and ionic bonding nature. The semiconducting behavior for $\mathrm{SbNSr}_{3}$ is also evident from the imaginary part of the dielectric function as presented in their work.

Haddadi et al. [48] investigated structural, elastic, and electronic properties of the hexagonal antiperovskites $\mathrm{SbNBa}_{3}$ and $\mathrm{BiNBa}_{3}$ using $\mathrm{Wu}$-Cohen generalized gradient approximation (GGA-WC). The authors achieved the band gap of $0.529 \mathrm{eV}$ for both of these materials which is consistent with the previous theoretical work [46]. Both materials show direct band gap semiconducting nature on ambient pressure. Figure 6 presents the pressure dependence on the band gaps of these materials. The band gap decreases with pressure and pressure-induced metallization is predicted at 7.95 and 8.02 $\mathrm{GPa}$ pressure for $\mathrm{SbNBa}_{3}$ and $\mathrm{BiNBa}_{3}$, respectively.

Hichour et al. [49] studied the structural and elastic properties of cubic $\mathrm{SbNBa}_{3}$ and $\mathrm{BiNBa}_{3}$ materials (while these materials are hexagonal experimentally [46]) comparing structural results with theoretical data from [45]. Jha and Gupta [50] also worked on the lattice dynamic study of antiperovskite compounds $\mathrm{AsNBa}_{3}$ and $\mathrm{SbNBa}_{3}$ in cubic structure. The authors presented metallic band structures of these materials which are in contradiction with the experimental work [46].

\section{Transition Metals Based Antiperovskite Materials}

Since 1960s, extensive research has been carried out on the different physical properties of manganese based antiperovskites materials with general formula $\mathrm{AXMn}_{3}$ (A is a metal or semiconducting elements and $\mathrm{X}$ is $\mathrm{C}$ or $\mathrm{N}$ ) [25]. In the last decade, after the discovery of superconductivity in $\mathrm{MgCNi}_{3}$ [28], Mn based antiperovskites gained huge attention of researchers all around the globe. Different properties like giant magnetoresistance and magnetocaloric effect (GMR) of $\mathrm{GaCMn}_{3}[22,51]$, negative or zero thermal expansion (NTE or ZTE) of $\mathrm{Cu}$ (Ge) $\mathrm{NMn}_{3}$ [52], nearly zero temperature coefficient of resistance (TCR) of $\mathrm{Ag}_{1-x} \mathrm{Cu}_{x} \mathrm{NMn}_{3}$ [53], and giant magnetostriction (MS) of $\mathrm{CuNMn}_{3}$ [24] are reported. Generally, these materials show metallic behavior. The $3 \mathrm{~d}$ 


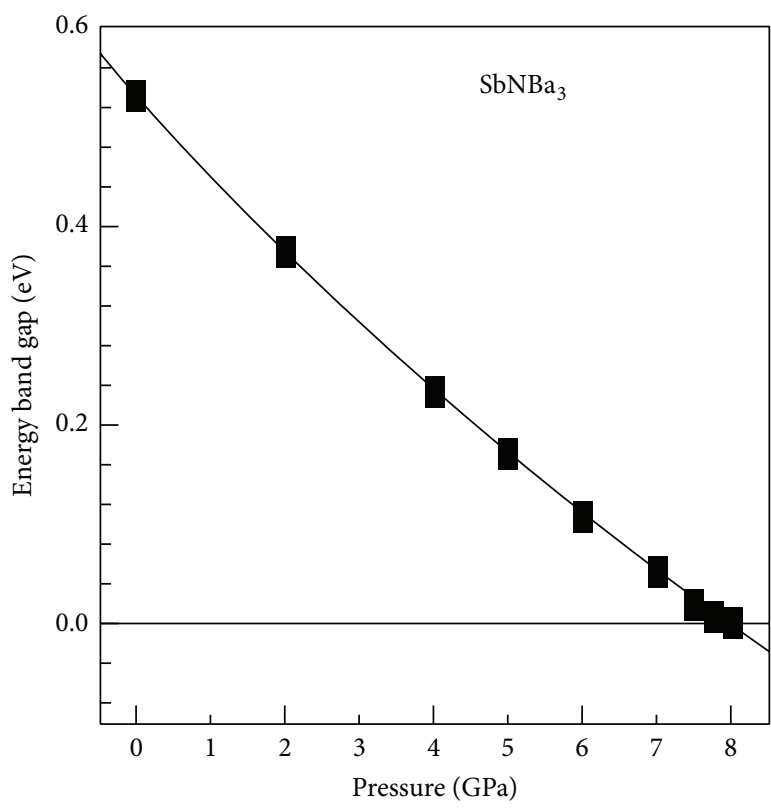

(a)

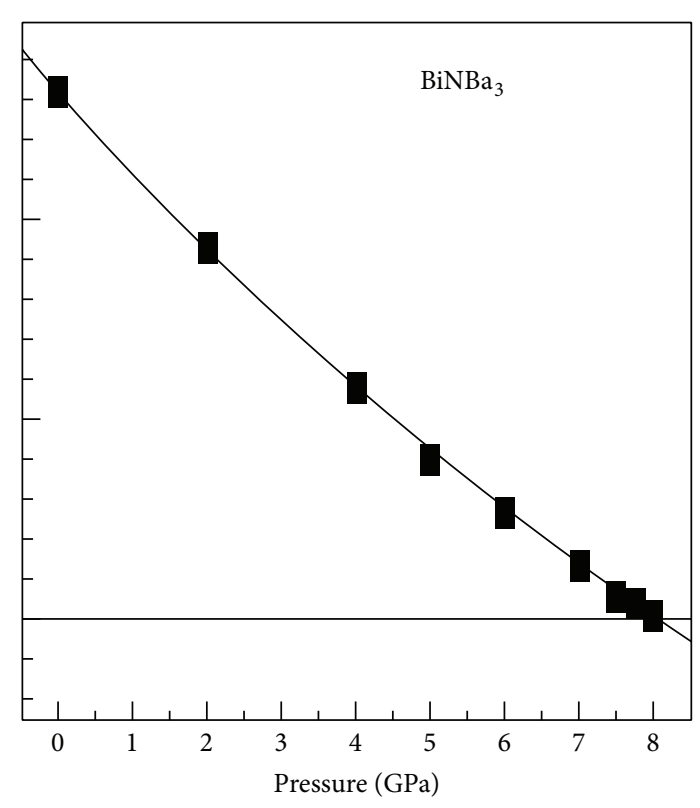

(b)

FIGURE 6: Band gap energies versus pressure for (a) $\mathrm{SbNSr}_{3}$ and (b) $\mathrm{BiNSr}_{3}$ reproduced with permission from [48].

orbitals of Mn have high density of states at Fermi level $\left(E_{F}\right)$ while hybridization between X-p states and Mn-d states is the main cause of wide conduction band crossing over the Fermi level [54]. Sun et al. [15] reported unusual phase separation and irregularity in the electronic transport properties of $\mathrm{ZnNMn}_{3}$. The authors further presented [55] the thermodynamic, electromagnetic, and structural properties of antiperovskite $\mathrm{SbNMn}_{3}$. The authors found that at room temperature the materials exist in tetragonal structure with lattice parameters $a=b=4.17994 \AA$ and $c=$ $4.27718 \AA$. Wang et al. [56] studied the structural, magnetic, electrical transport properties, and reversible roomtemperature magnetocaloric effect in antiperovskite compound $\mathrm{AlCMn}_{3}$. The material shows good metallic behavior with ferromagnetic-paramagnetic phase transition at $T_{C}=$ $287 \mathrm{~K} . \mathrm{GaCMn}_{3}$ is a widely studied antiperovskites material $[22,57,58]$. It is a metallic material with antiferromagnetic (AFM) behavior at ambient temperature. $\mathrm{GaCMn}_{3}$ shows transition and becomes ferromagnet (FM) at $163.9 \mathrm{~K}$ and paramagnet (PM) at $245.8 \mathrm{~K}$ [22]. Shim et al. [59] studied the electronic properties of $\mathrm{GaCMn}_{3}, \mathrm{ZnCMn}_{3}, \mathrm{SnCMn}_{3}$, and $\mathrm{ZnNMn}_{3}$ using linearized muffin-tin orbital (LMTO) method in the local spin density approximation (LSDA). The electronic properties are calculated in paramagnetic state for these materials. The density of states for $\mathrm{GaCMn}_{3}$ show strong hybridization between $\mathrm{Mn}-3 \mathrm{~d}$ and C-2p states which increases bonding states between $-3 \mathrm{eV}$ and $-7 \mathrm{eV}$ whereas the nonbonding states $\mathrm{Mn}-3 \mathrm{~d}$ are at the Fermi level.

After the discovery of superconductivity in $\mathrm{MgCNi}_{3}$ [28], $\mathrm{Ni}$ based isostructural antiperovskites materials have gained enormous attention among the researchers [29]. Uehara et al. $[60,61]$ reported superconductivity in $\mathrm{CdCNi}_{3}$ and $\mathrm{ZnNNi}_{3}$ antiperovskites with transition temperatures of 3.2 and $3 \mathrm{~K}$, respectively. Shim et al. [62] studied the electronic properties of $\mathrm{MgXNi}_{3}(\mathrm{X}=\mathrm{B}, \mathrm{C}$, and $\mathrm{N})$. Ni-3d and C-2p states form the antibonding subband near Fermi level in $\mathrm{MgCNi}_{3}$ with $\mathrm{Ni}-3 \mathrm{~d}$ dominant character. The DOS for $\mathrm{MgXNi}_{3}$ reveals that changing $\mathrm{X}$ changes the density of states near the Fermi level with $\mathrm{B}-2 \mathrm{p}$ state in $\mathrm{MgBNi}_{3}$ located higher in energy than the $\mathrm{C}-2 \mathrm{p}$ state of $\mathrm{MgCNi}_{3}$, and so the hybridization with $\mathrm{Ni}-3 \mathrm{~d}$ is stronger.

Johannes and Pickett [63] studied the electronic structure of $\mathrm{ZnCNi}_{3}$ and showed that no superconductivity is found in this material down to $2 \mathrm{~K}$. According to the authors the absence of superconductivity in $\mathrm{ZnCNi}_{3}$ as compared to $\mathrm{MgCNi}_{3}$ can only be explained by assuming $\mathrm{Mg}$ deficient in this material. Wu et al. [64] investigated the structure, electronic, and magnetic state of $\mathrm{InCNi}_{3}$ antiperovskite material using LDA and GGA. The authors reported that the material is paramagnetic with strong hybridization between $\mathrm{Ni}-3 \mathrm{~d}$ and $\mathrm{C}-2 \mathrm{p}$ states. Hou studied the elastic properties and electronic structures of $\mathrm{InNCO}_{3}$ and $\mathrm{InNNi}_{3}$ antiperovskite materials [65]. Due to the different strength of $2 p-3 d$ hybridization for the $\mathrm{N}-\mathrm{Co}$ atoms in $\mathrm{InNCo}_{3}$ and the $\mathrm{N}-\mathrm{Ni}$ atoms in $\mathrm{InNNi}_{3}, \mathrm{InNCO}_{3}$ is ferromagnetic while the ground state of $\mathrm{InNNi}_{3}$ is nonmagnetic. Li et al. [66] investigated the mechanical and electronic properties of $\mathrm{MNNi}_{3}(\mathrm{M}=\mathrm{Zn}$, $\mathrm{Mg}$, or $\mathrm{Cd}$ ). The maximum states are occupied by $\mathrm{Ni}$ $3 \mathrm{~d}$ and N-2p hybridization near the Fermi level while M elements have very small contribution here. However, this small contribution of $\mathrm{M}$ elements may cause a small shift in the bands near the Fermi level, resulting in superconductivity in $\mathrm{ZnNNi}_{3}$ at $T_{\mathrm{C}} \approx 3 \mathrm{~K}$ while the other two compounds do not show superconductivity.

Grandjeant and Gerard [67] synthesized and studied the structural and magnetic properties of $\mathrm{ACFe}_{3}(\mathrm{~A}=\mathrm{Al}$, 
$\mathrm{Zn}, \mathrm{Ga}, \mathrm{Sn}$, and $\mathrm{Ge}$ ) antiperovskites materials. Fe based antiperovskites materials have been investigated by different researchers [68-72]. Ivanovskii et al. [73-75] reported the electronic properties of these materials, while the electronic band structure of the cubic antiperovskites $\mathrm{M}_{3} \mathrm{M}^{\prime} \mathrm{C}(\mathrm{M}=\mathrm{Mn}$, Fe; $\mathrm{M}^{\prime}=\mathrm{Zn}, \mathrm{Al}, \mathrm{Ga}, \mathrm{Sn}$ ) in ferromagnetic state is calculated by using LMTO-ASA nonempirical self-consistent method [73]. All materials have high density of states at Fermi level mainly due to $\mathrm{Fe}-3 \mathrm{~d}$ states and show metallic behavior. Furthermore, the authors show that these materials are ferromagnetic in nature.

Tian and Nemoto [76] performed transmission electron microscopy on $\mathrm{AlCTi}_{3}$. Subsequently different researchers investigated the physical properties like electronic, mechanical, and thermal properties of this material using different techniques [77-81]. Yu-Lei [78] studied the electronic properties of this material using GGA potential. The band structure presented by the author shows that this is a metallic material. The density of states is also discussed for the understanding of the different states at Fermi level. The strong hybridization between Ti-3d and Al-3p states and between Ti-3d and C$2 p$ states stabilizes the structure of $\mathrm{Ti}_{3} \mathrm{AlC}$. Medkour et al. [81] studied the structural, elastic, and electronic properties of $\mathrm{ACTi}_{3}(\mathrm{~A}=\mathrm{Al}$, In, and $\mathrm{Tl})$ antiperovskites materials using first principle calculations. All of these materials show metallic character with strong ionic covalent bonds between $\mathrm{Ti}$ and $\mathrm{C}$ atoms, and ionic bonds along $\mathrm{A}$ and $\mathrm{Ti}$ atoms. The authors suggest that the stiffness decreases with an increase in the antibonding state between $\mathrm{Ti}$ and $\mathrm{A}$ atoms.

Brady et al. [82, 83] worked on the synthesis of chromium based nitride antiperovskites $\mathrm{PtNCr}_{3}$. Wiendlocha et al. [84] studied the electronic properties, superconductivity, and magnetism in $\mathrm{GaNCr}_{3}$ and $\mathrm{RhNCr}_{3}$ materials. The band structures of these materials presented in the paper show that both materials are metallic in nature. The spinpolarized calculations show nonferromagnetic ground state for both compounds. The authors are of the opinion that there may be superconductivity in these materials because of the high values of electronic part of electron-phonon coupling constant. Tütüncü and Srivastava [85] theoretically investigated structural, electronic, vibrational, and superconducting properties of the cubic antiperovskite $\mathrm{RhNCr}_{3}$. The authors claim that this material is metallic with superconducting nature below $17 \mathrm{~K}$.

Shao et al. [86] studied the structural, elastic, and electronic properties of $\mathrm{ACCr}_{3}(\mathrm{~A}=\mathrm{Al}$ and $\mathrm{Ga})$ antiperovskites materials using first principles methods. The analysis of formation energies shows that both materials can be synthesized at ambient pressure and are nonmagnetic in nature. The band structures show that the materials are metallic in nature. Shao et al. [87] investigated the electronic structure, magnetic properties, and lattice dynamics of the $\mathrm{AXCr}_{3}(\mathrm{X}=\mathrm{C}$ or $\mathrm{N}, \mathrm{A}=\mathrm{Zn}, \mathrm{Al}, \mathrm{Ga}, \mathrm{Sn}, \mathrm{Ag}, \mathrm{Cd}, \mathrm{Mg}$, and In) using ABINIT code. The authors claim that among the nitride materials only $\mathrm{ZnNCr}_{3}, \mathrm{AlNCr}_{3}, \mathrm{GaNCr}_{3}$, and $\mathrm{SnNCr}_{3}$ can be synthesized for having negative formation energies. Furthermore, all materials show metallic nature with $\mathrm{AlCCr}_{3}, \mathrm{GaCCr}_{3}$, and $\mathrm{ZnNCr}_{3}$ being the potential candidates of superconductivity.

\section{Summary}

We present the research progress on theoretical electronic properties of carbon and nitrogen based antiperovskite materials comparing with the available experimental data. In a nutshell, we can classify antiperovskite materials into two groups: materials having an element of group-IIA of the periodic table and the materials having a transition metal at the face centers of the unit cell of these materials. The former are mostly semiconductors while the latter are generally metals. Literature reveals that enormous research is being carried out on the different physical properties of antiperovskites. Superconductivity is found in some metallic materials though there is still room for research in this aspect. Similarly magnetism is one of the most important features of antiperovskites and properties like giant magnetoresistance, magnetocaloric effect, and temperature coefficient of resistivity are important industrial utilities. Thermoelectric properties of these materials have been less explored. There are many semiconducting materials which can be potential candidates for thermoelectric properties as these materials have suitable band gaps and dense electronic states near Fermi level. It is also clear from these studies that despite vast studies on the electronic properties of these materials still there are some ambiguities which need to be addressed. On one hand, exact band gaps of some materials are not known, while on the other hand the experimentally known band gaps have not been reproduced theoretically. As the electronic properties are very important in determining different physical properties of materials, therefore, we hope that this work will benefit the researchers working in this field.

\section{Conflict of Interests}

The authors declare that there is no conflict of interests regarding the publication of this paper.

\section{References}

[1] M. Y. Chern, D. A. Vennos, and F. J. Disalvo, "Synthesis, structure, and properties of anti-perovskite nitrides $\mathrm{Ca}_{3} \mathrm{MN}$, $\mathrm{M}=\mathrm{P}, \mathrm{As}, \mathrm{Sb}, \mathrm{Bi}, \mathrm{Ge}, \mathrm{Sn}$, and Pb," Journal of Solid State Chemistry, vol. 96, no. 2, pp. 415-425, 1992.

[2] L. S. Cavalcante, V. S. Marques, J. C. Sczancoski et al., "Synthesis, structural refinement and optical behavior of $\mathrm{CaTiO}_{3}$ powders: a comparative study of processing in different furnaces," Chemical Engineering Journal, vol. 143, no. 1-3, pp. 299-307, 2008.

[3] R. H. Langley, C. K. Schmitz, and M. B. Langley, "The synthesis and characterization of some fluoride perovskites, an undergraduate experiment in solid state chemistry," Journal of Chemical Education, vol. 61, no. 7, pp. 643-645, 1984.

[4] S. Piskunov, E. Heifets, R. I. Eglitis, and G. Borstel, "Bulk properties and electronic structure of $\mathrm{SrTiO}_{3}, \mathrm{BaTiO}_{3}, \mathrm{PbTiO}_{3}$ perovskites: an ab initio HF/DFT study," Computational Materials Science, vol. 29, no. 2, pp. 165-178, 2004.

[5] M. Kirchner, W. Schnelle, and R. Niewa, "Inverse perovskites $\left(\mathrm{Eu}_{3} \mathrm{O}\right) \mathrm{E}$ with $\mathrm{E}=\mathrm{Sn}$, in-preparation, crystal structures and physical properties," Zeitschrift für Anorganische und Allgemeine Chemie, vol. 632, no. 4, pp. 559-564, 2006. 
[6] H. Gotoh, Y. Takeda, H. Asano, J. Zhong, A. Rajanikanth, and K. Hono, "Antiferromagnetism and spin polarization in double perovskite SrLaVMoO," Applied Physics Express, vol. 2, no. 1, 2009.

[7] A. Pabst, "The crystal structure of sulphohalite," Zeitschrift für Kristallographie, vol. 89, pp. 514-517, 1934.

[8] M. Sahnoun, M. Zbiri, C. Daul, R. Khenata, H. Baltache, and M. Driz, "Full potential calculation of structural, electronic and optical properties of $\mathrm{KMgF}_{3}$," Materials Chemistry and Physics, vol. 91, no. 1, pp. 185-191, 2005.

[9] D. C. Arnold, K. S. Knight, F. D. Morrison, and P. Lightfoot, "Ferroelectric-paraelectric transition in $\mathrm{BiFeO}_{3}$ : crystal structure of the orthorhombic $\beta$ phase," Physical Review Letters, vol. 102, no. 2, Article ID 027602, 2009.

[10] R. V. Shpanchenko, V. V. Chernaya, A. A. Tsirlin et al., "Synthesis, structure, and properties of new perovskite $\mathrm{PbVO}_{3}$," Chemistry of Materials, vol. 16, no. 17, pp. 3267-3273, 2004.

[11] J. Frantti, Y. Fujioka, J. Zhang et al., "The factors behind the morphotropic phase boundary in piezoelectric perovskites," The Journal of Physical Chemistry B, vol. 113, no. 23, pp. 7967-7972, 2009.

[12] T. Tohei, H. Moriwake, H. Murata et al., "Geometric ferroelectricity in rare-earth compounds $\mathrm{RGaO}_{3}$ and $\mathrm{RInO}_{3}$," Physical Review B-Condensed Matter and Materials Physics, vol. 79, no. 14, Article ID 144125, 2009.

[13] S. V. Krivovichev, "Minerals with antiperovskite structure: a review," Zeitschrift für Kristallographie, vol. 223, no. 1-2, pp. 109113, 2008.

[14] M. Sieberer, P. Mohn, and J. Redinger, "Role of carbon in $\mathrm{AlCNi}_{3}$ and $\mathrm{GaCNi}_{3}$ : a density functional theory study," Physical Review B, vol. 75, no. 2, Article ID 024431, 2007.

[15] Y. Sun, C. Wang, Q. Huang et al., "Neutron diffraction study of unusual phase separation in the antiperovskite nitride $\mathrm{Mn}_{3} \mathrm{ZnN}$,' Inorganic Chemistry, vol. 51, no. 13, pp. 7232-7236, 2012.

[16] A. Bouhemadou and R. Khenata, "Ab initio study of the structural, elastic, electronic and optical properties of the antiperovskite $\mathrm{SbNMg}_{3}$," Computational Materials Science, vol. 39, no. 4, pp. 803-807, 2007.

[17] C. M. I. Okoye, "First-principles optical calculations of $\mathrm{AsNMg}_{3}$ and $\mathrm{SbNMg}_{3}, "$ Materials Science and Engineering B, vol. 130, no. 1-3, pp. 101-107, 2006.

[18] S. V. Ovsyannikov and V. V. Shchennikov, "High-pressure routes in the thermoelectricity or how one can improve a performance of thermoelectrics," Chemistry of Materials, vol. 22, no. 3, pp. 635-647, 2010.

[19] M. B. Ricoult, L. A. Moore, C. M. Smith, and T. P. S. Clair, "Patent Application Publication," US 2014/0225022 A1, 2014.

[20] V. Thangadurai and W. Weppner, "Recent progress in solid oxide and lithium ion conducting electrolytes research," Ionics, vol. 12, no. 1, pp. 81-92, 2006.

[21] Y. Zhang, Y. Zhao, and C. Chen, "Ab initio study of the stabilities of and mechanism of superionic transport in lithium-rich antiperovskites," Physical Review B, vol. 87, no. 13, Article ID 134303, 2013.

[22] K. Kamishima, T. Goto, H. Nakagawa et al., "Giant magnetoresistance in the intermetallic compound $\mathrm{Mn}_{3} \mathrm{GaC}$," Physical Review B-Condensed Matter and Materials Physics, vol. 63, no. 2, Article ID 024426, 2001.
[23] Y. Sun, C. Wang, L. Chu, Y. Wen, M. Nie, and F. Liu, "Low temperature coefficient of resistivity induced by magnetic transition and lattice contraction in $\mathrm{Mn}_{3} \mathrm{NiN}$ compound," Scripta Materialia, vol. 62, no. 9, pp. 686-689, 2010.

[24] K. Asano, K. Koyama, and K. Takenaka, "Magnetostriction in $\mathrm{Mn}_{3} \mathrm{CuN}$," Applied Physics Letters, vol. 92, no. 16, Article ID 161909, 2008.

[25] P. Tong, B.-S. Wang, and Y.-P. Sun, "Mn-based antiperovskite functional materials: review of research," Chinese Physics B, vol. 22, no. 6, Article ID 067501, 2013.

[26] K. Takenaka and H. Takagi, "Giant negative thermal expansion in Ge-doped anti-perovskite manganese nitrides," Applied Physics Letters, vol. 87, no. 26, Article ID 261902, pp. 1-3, 2005.

[27] Y. Nakamura, K. Takenaka, A. Kishimoto, and H. Takagi, "Mechanical properties of metallic perovskite $\mathrm{Mn}_{3} \mathrm{Cu}_{0.5} \mathrm{Ge}_{0.5} \mathrm{~N}$ : high-stiffness isotropic negative thermal expansion material," Journal of the American Ceramic Society, vol. 92, no. 12, pp. 2999-3003, 2009.

[28] T. He, Q. Huang, A. P. Ramirez et al., "Superconductivity in the non-oxide perovskite $\mathrm{MgCNi}_{3}$," Nature, vol. 411, no. 6833, pp. 54-59, 2001.

[29] P. Tong and Y. P. Sun, "Research progress on Ni-based antiperovskite compounds," Advances in Condensed Matter Physics, vol. 2012, Article ID 903239, 9 pages, 2012.

[30] D. Fruchart and E. F. Bertaut, "Magnetic studies of the metallic perovskite-type compounds of manganese," Journal of the Physical Society of Japan, vol. 44, no. 3, article 781, 1978.

[31] M. Moakafi, R. Khenata, A. Bouhemadou, F. Semari, A. H. Reshak, and M. Rabah, "Elastic, electronic and optical properties of cubic antiperovskites $\mathrm{SbNCa}_{3}$ and $\mathrm{BiNCa}_{3}$," Computational Materials Science, vol. 46, no. 4, pp. 1051-1057, 2009.

[32] M. Hichour, R. Khenata, D. Rached et al., "FP-APW+lo study of the elastic, electronic and optical properties for the cubic antiperovskite $\mathrm{ANSr}_{3}(A=\mathrm{As}, \mathrm{Sb}$ and $\mathrm{Bi}$ ) under pressure effect," Physica B: Condensed Matter, vol. 405, no. 7, pp. 1894-1900, 2010.

[33] R. Diehl, High-Power Diode Lasers, vol. 78, Springer, 2000, Edited by C. E. Ascheron.

[34] M. M. Schwartz, Encyclopedia of Materials, Parts, and Finishes, CRC Press, New York, NY, USA, 2002.

[35] G. N. Petzow, F. Aldinger, S. Jönsson et al., "Beryllium and beryllium compounds," in Ullmann's Encyclopedia of Industrial Chemistry, 2005.

[36] D. A. Papaconstantopoulos and W. E. Pickett, “Ternary nitrides $\mathrm{BiNCa}_{3}$ and $\mathrm{PbNCa}_{3}$ : unusual ionic bonding in the antiperovskite structure," Physical Review B, vol. 45, no. 8, pp. 40084012, 1992.

[37] P. R. Vansant, P. E. van Camp, V. E. van Doren, and J. L. Martins, "Variable-cell-shape-based structural optimization applied to calcium nitrides," Physical Review B-Condensed Matter and Materials Physics, vol. 57, no. 13, pp. 7615-7620, 1998.

[38] M. Y. Chern, F. J. Disalvo, J. B. Parise, and J. A. Goldstone, "The structural distortion of the anti-perovskite nitride $\mathrm{Ca}_{3} \mathrm{AsN}$," Journal of Solid State Chemistry, vol. 96, no. 2, pp. 426-435, 1992.

[39] M. Bilal, I. Ahmad, H. A. R. Aliabad, and S. J. Asadabadi, "Detailed DFT studies of the band profiles and optical properties of antiperovskites $\mathrm{SbNCa}_{3}$ and $\mathrm{BiNCa}_{3}$," Computational Materials Science, vol. 85, pp. 310-315, 2014.

[40] E. O. Chi, W. S. Kim, N. H. Hur, and D. Jung, "New Mg-based antiperovskites $\mathrm{PnNMg}_{3}(\mathrm{Pn}=\mathrm{As}, \mathrm{Sb})$," Solid State Communications, vol. 121, no. 6-7, pp. 309-312, 2002. 
[41] I. R. Shein and A. L. Ivanovskii, "Electronic band structure and chemical bonding in the new antiperovskites $\mathrm{AsNMg}_{3}$ and $\mathrm{SbNMg}_{3}$," Journal of Solid State Chemistry, vol. 177, no. 1, pp. 6164, 2004.

[42] A. Bouhemadou, R. Khenata, M. Chegaar, and S. Maabed, "First-principles calculations of structural, elastic, electronic and optical properties of the antiperovskite $\mathrm{AsNMg}_{3}$," Physics Letters, Section A: General, Atomic and Solid State Physics, vol. 371, no. 4, pp. 337-343, 2007.

[43] T. Belaroussi, B. Amrani, T. Benmessabih, N. Iles, and F. Hamdache, "Structural and thermodynamic properties of antiperovskite SbNMg 3 ," Computational Materials Science, vol. 43, no. 4, pp. 938-942, 2008.

[44] K. Amara, M. Zemouli, M. Elkeurti, A. Belfedal, and F. Saadaoui, "First-principles study of $\mathrm{XNMg}_{3}(\mathrm{X}=\mathrm{P}, \mathrm{As}$, Sb and $\mathrm{Bi}$ ) antiperovskite compounds," Journal of Alloys and Compounds, vol. 576, pp. 398-403, 2013.

[45] B. V. Beznosikov, "Predicted nitrides with an antiperovskite structure," Journal of Structural Chemistry, vol. 44, no. 5, pp. 885-888, 2003.

[46] F. Gäbler, M. Kirchner, W. Schnelle et al., “ $\left(\mathrm{Sr}_{3} \mathrm{~N}\right) \mathrm{E}$ and $\left(\mathrm{Ba}_{3} \mathrm{~N}\right) \mathrm{E}$ $(\mathrm{E}=\mathrm{Sb}, \mathrm{Bi})$ : synthesis, crystal structures, and physical properties," Zeitschrift für Anorganische und Allgemeine Chemie, vol. 630, no. 13-14, pp. 2292-2298, 2004.

[47] K. Haddadi, A. Bouhemadou, L. Louail, F. Rahal, and S. Maabed, "Prediction study of the structural, elastic and electronic properties of $\mathrm{ANSr}_{3}(\mathrm{~A}=\mathrm{As}, \mathrm{Sb}$ and $\mathrm{Bi})$," Computational Materials Science, vol. 46, no. 4, pp. 881-886, 2009.

[48] K. Haddadi, A. Bouhemadou, and L. Louail, "Structural, elastic and electronic properties of the hexagonal anti-perovskites $\mathrm{SbNBa}_{3}$ and $\mathrm{BiNBa}_{3}$," Computational Materials Science, vol. 48, no. 4, pp. 711-718, 2010.

[49] M. Hichour, D. Rached, M. Rabah, S. Benalia, R. Khenata, and F. Semari, "Structural and elastic properties of antiperovskites $\mathrm{XNBa}_{3}(\mathrm{X}=\mathrm{As}, \mathrm{Sb})$ under pressure effect," Physica B: Condensed Matter, vol. 404, no. 21, pp. 4034-4038, 2009.

[50] P. K. Jha and S. K. Gupta, "First principles lattice dynamical study of the cubic antiperovskite compounds $\mathrm{AsNBa}_{3}$ and $\mathrm{SbNBa}_{3}$," Solid State Communications, vol. 150, no. 35-36, pp. 1650-1655, 2010.

[51] M.-H. Yu, L. H. Lewis, and A. R. Moodenbaugh, "Large magnetic entropy change in the metallic antiperovskite Mn3GaC," Journal of Applied Physics, vol. 93, no. 12, pp. 10128-10130, 2003.

[52] S. Iikubo, K. Kodama, K. Takenaka, H. Takagi, M. Takigawa, and S. Shamoto, "Local lattice distortion in the giant negative thermal expansion material $\mathrm{Mn}_{3} \mathrm{Cu}_{1-x} \mathrm{Ge}_{x} \mathrm{~N}$," Physical Review Letters, vol. 101, no. 20, Article ID 205901, 2008.

[53] K. Takenaka, A. Ozawa, T. Shibayama, N. Kaneko, T. Oe, and C. Urano, "Extremely low temperature coefficient of resistance in antiperovskite $\mathrm{Mn}_{3} \mathrm{Ag}_{1-x} \mathrm{Cu}_{x} \mathrm{~N}$," Applied Physics Letters, vol. 98, no. 2, Article ID 022103, 2011.

[54] J. H. Shim, S. K. Kwon, and B. I. Min, "Electronic structure of metallic antiperovskite compound $\mathrm{GaCMn}_{3}$," Physical Review $B$, vol. 66, no. 2, Article ID 020406, 2002.

[55] Y. Sun, Y.-F. Guo, Y. Tsujimoto et al., "Thermodynamic, electromagnetic, and lattice properties of antiperovskite Mn3SbN," Advances in Condensed Matter Physics, vol. 2013, Article ID 286325, 5 pages, 2013.

[56] B. S. Wang, J. C. Lin, P. Tong et al., "Structural, magnetic, electrical transport properties, and reversible room-temperature magnetocaloric effect in antipervoskite compound $\mathrm{AlCMn}_{3}$,"
Journal of Applied Physics, vol. 108, no. 9, Article ID 093925, 2010.

[57] K. Koyama, T. Kanomata, T. Watanabe, T. Suzuki, H. Nishihara, and $\mathrm{K}$. Watanabe, "X-ray powder diffraction studies of $\mathrm{Mn}_{3} \mathrm{Ga}_{0.97} \mathrm{Al}_{0.03} \mathrm{C}$ in magnetic fields," Materials Transactions, vol. 47, no. 3, pp. 492-495, 2006.

[58] B. S. Wang, P. Tong, Y. P. Sun et al., "Enhanced giant magnetoresistance in Ni-doped antipervoskite compounds $\mathrm{GaCMn}_{3-x} \mathrm{Ni}_{x}$ $(x=0.05,0.10)$," Applied Physics Letters, vol. 95, no. 22, Article ID 222509, 2009.

[59] J. H. Shim, S. K. Kwon, and B. I. Min, "Electronic structure of metallic antiperovskite compound $\mathrm{GaCMn}_{3}$," http://arxiv.org/ pdf/cond-mat/0201328.pdf.

[60] M. Uehara, T. Yamazaki, T. Kôri, T. Kashida, Y. Kimishima, and I. Hase, "Superconducting properties of $\mathrm{CdCNi}_{3}$," Journal of the Physical Society of Japan, vol. 76, no. 3, Article ID 034714, 2007.

[61] M. Uehara, A. Uehara, K. Kozawa, and Y. Kimishima, "New antiperovskite-type superconductor $\mathrm{ZnN}_{y} \mathrm{Ni}_{3}$," Journal of the Physical Society of Japan, vol. 78, no. 3, Article ID 033702, 2009.

[62] J. H. Shim, S. K. Kwon, and B. I. Min, "Electronic structures of antiperovskite superconductors $\mathrm{MgXNi}_{3}(\mathrm{X}=\mathrm{B}, \mathrm{C}$, and $\mathrm{N})$," Physical Review B, vol. 64, no. 18, Article ID 180510, 2001.

[63] M. D. Johannes and W. E. Pickett, "Electronic structure of $\mathrm{ZnCNi}_{3}$," Physical Review B-Condensed Matter and Materials Physics, vol. 70, no. 6, Article ID 060507, 2004.

[64] S. Q. Wu, Z. F. Hou, and Z. Z. Zhu, "Electronic structure and magnetic state of $\mathrm{InCNi}_{3}$," Physica B: Condensed Matter, vol. 403, no. 23-24, pp. 4232-4235, 2008.

[65] Z. F. Hou, "Elastic properties and electronic structures of antiperovskite-type $\mathrm{InNCo}_{3}$ and $\mathrm{InNNi}_{3}$," Solid State Communications, vol. 150, no. 39-40, pp. 1874-1879, 2010.

[66] C. Li, W. G. Chen, F. Wang et al., "First-principles investigation of mechanical and electronic properties of $\mathrm{MNNi}_{3}(\mathrm{M}=\mathrm{Zn}, \mathrm{Mg}$, or Cd)," Journal of Applied Physics, vol. 105, no. 12, Article ID 123921, 2009.

[67] F. Grandjeant and A. Gerard, "Study by Mossbauer spectroscopy of the series of perovskite carbides $\mathrm{M}_{3} \mathrm{M}^{\prime} \mathrm{C}$ with $\mathrm{M}=\mathrm{Fe}$ or $\mathrm{Mn}$, and $\mathrm{M}^{\prime}=\mathrm{Al}, \mathrm{Ga}, \mathrm{Ge}, \mathrm{Zn}, \mathrm{Sn}$," Journal of Physics F: Metal Physics, vol. 6, pp. 451-467, 1976.

[68] T. Maruoka and R. O. Suzuki, "The phase equilibria and seebeck coefficient of $(\mathrm{Co}, \mathrm{M})_{3} \mathrm{AlC}(\mathrm{M}=\mathrm{Fe}$ or $\mathrm{Ni})$," Materials Transactions, vol. 47, no. 6, pp. 1422-1427, 2006.

[69] B. S. Wang, P. Tong, Y. P. Sun et al., "Observation of spin-glass behavior in antiperovskite compound $\mathrm{SnCFe}_{3}$," Applied Physics Letters, vol. 97, no. 4, Article ID 042508, 2010.

[70] S. Lin, B. S. Wang, J. C. Lin et al., "The magnetic, electrical transport and thermal transport properties of Fe-based antipervoskite compounds $\mathrm{ZnC}_{x} \mathrm{Fe}_{3}$," Journal of Applied Physics, vol. 110, no. 8, Article ID 083914, 2011.

[71] S. Lin, B. S. Wang, P. Tong et al., "Magnetism and large reversible room-temperature magnetocaloric properties of antiperovskite compounds $\mathrm{ZnC}_{1-x} \mathrm{~N}_{x} \mathrm{Fe}_{3-2 x} \mathrm{Mn}_{2 x}(0 \leq x \leq 1)$," Journal of Alloys and Compounds, vol. 572, pp. 145-149, 2013.

[72] S. Lin, B. S. Wang, J. C. Lin et al., "Tunable room-temperature zero temperature coefficient of resistivity in antiperovskite compounds $\mathrm{Ga}_{1-x} \mathrm{CFe}_{3}$ and $\mathrm{Ga}_{1-y} \mathrm{Al}$ yCFe 3 ," Applied Physics Letters, vol. 101, no. 1, Article ID 011908, 2012.

[73] A. L. Ivanovskii, R. F. Sabiryanov, and A. N. Skazkin, "Band structure and magnetic properties of $\mathrm{M}_{3} \mathrm{M}^{\prime} \mathrm{C}$ antiperovskites $(\mathrm{M}=\mathrm{Mn}, \mathrm{Fe} ; \mathrm{M} /=\mathrm{Zn}, \mathrm{Al}, \mathrm{Ga}, \mathrm{Sn})$," Physics of the Solid State, vol. 40, no. 9, pp. 1516-1519, 1998. 
[74] A. L. Ivanovskii, I. S. Elfimov, A. N. Skazkin, V. M. Zhukovski, and G. P. Shvekin, "Zone structure of paramagnetic perovskitelike manganese and iron alumocarbides," Fizika Tverdogo Tela, vol. 37, no. 12, pp. 3738-3743, 1995, Translated in Physics of the Solid State, vol. 37, p. 2061, 1995.

[75] A. L. Ivanovskii, Zhurnal Neorganicheskoi Khimii, vol. 41, p. 650, 1996.

[76] W. H. Tian and M. Nemoto, "Precipitation behavior of (Al,Ag) ${ }_{3} \mathrm{Ti}$ and $\mathrm{Ti}_{3} \mathrm{AlC}$ in $\mathrm{Ll}_{0}$-TiAl in Ti-Al-Ag system," Intermetallics, vol. 7, no. 11, pp. 1261-1269, 1999.

[77] V. Kanchana, "Mechanical properties of $\mathrm{Ti}_{3} \mathrm{AlX}(\mathrm{X}=\mathrm{C}, \mathrm{N})$ : Ab initio study," Europhysics Letters, vol. 87, no. 2, Article ID 26006, 2009.

[78] D. Yu-Lei, "Electronic structure and elastic properties of $\mathrm{Ti}_{3} \mathrm{AlC}$ from first-principles calculations," Chinese Physics Letters, vol. 26, no. 11, Article ID 117102, 2009.

[79] A. Ganguly, M. W. Barsoum, and J. Schuster, "The $1300^{\circ} \mathrm{C}$ isothermal section in the Ti-In-C ternary phase diagram," Journal of the American Ceramic Society, vol. 88, no. 5, pp. 12901296, 2005.

[80] X. Zhang, X. Wang, F. Li, and Y. Zhou, "Mechanical and thermal properties of antiperovskite $\mathrm{Ti}_{3} \mathrm{AlC}$ prepared by an in situ reaction/hot-pressing route," Journal of the American Ceramic Society, vol. 92, no. 11, pp. 2698-2703, 2009.

[81] Y. Medkour, A. Roumili, M. Boudissa, and D. Maouche, "Structural, elastic and electronic properties of ACTi3 $(\mathrm{A}=\mathrm{Al}$, In and Tl) antiperovskite," Solid State Communications, vol. 149, no. 2324, pp. 919-922, 2009.

[82] M. P. Brady, D. T. Hoelzer, E. A. Payzant et al., "Templated growth of a complex nitride island dispersion through an internal nitridation reaction," Journal of Materials Research, vol. 16, no. 10, pp. 2784-2787, 2001.

[83] M. P. Brady, S. K. Wrobel, T. A. Lograsso et al., "Synthesis of ternary nitrides from intermetallic precursors: modes of nitridation in model $\mathrm{Cr}_{3} \mathrm{Pt}$ alloys to form $\mathrm{Cr}_{3} \mathrm{PtN}$ antiperovskite and application to other systems," Chemistry of Materials, vol. 16, no. 10, pp. 1984-1990, 2004.

[84] B. Wiendlocha, J. Tobola, S. Kaprzyk, and D. Fruchart, "Electronic structure, superconductivity and magnetism study of $\mathrm{Cr}_{3} \mathrm{GaN}$ and $\mathrm{Cr}_{3} \mathrm{RhN}$," Journal of Alloys and Compounds, vol. 442, no. 1-2, pp. 289-291, 2007.

[85] H. M. Tütüncü and G. P. Srivastava, "Phonons and superconductivity in the cubic perovskite $\mathrm{Cr}_{3} \mathrm{RhN}$," Journal of Applied Physics, vol. 112, no. 9, Article ID 093914, 2012.

[86] D. F. Shao, W. J. Lu, S. Lin, P. Tong, and Y. P. Sun, "Structural, elastic, and electronic properties of antiperovskite chromiumbased carbides $\mathrm{ACCr}_{3}(\mathrm{~A}=\mathrm{Al}$ and Ga)," Advances in Condensed Matter Physics, vol. 2013, Article ID 136274, 7 pages, 2013.

[87] D. F. Shao, W. J. Lu, P. Tong, S. Lin, J. C. Lin, and Y. P. Sun, "Prediction of superconductivity of $3 d$ transition-metal based antiperovskites via magnetic phase diagram," Journal of the Physical Society of Japan, vol. 83, Article ID 054704, 10 pages, 2013. 

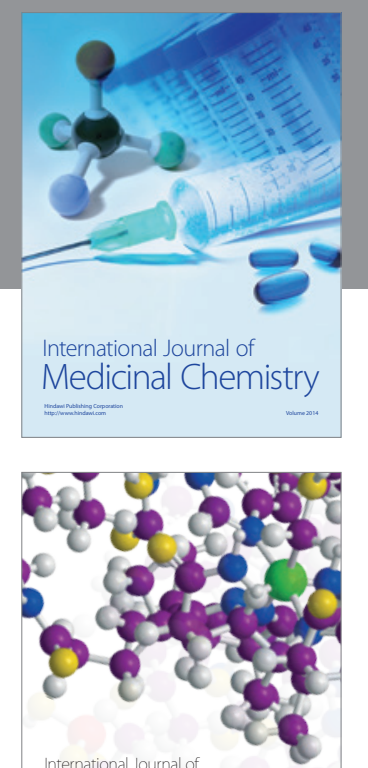

\section{Carbohydrate} Chemistry

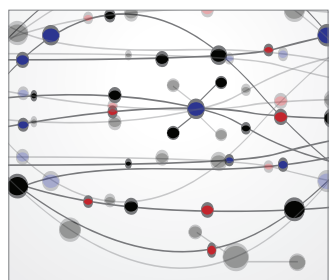

The Scientific World Journal
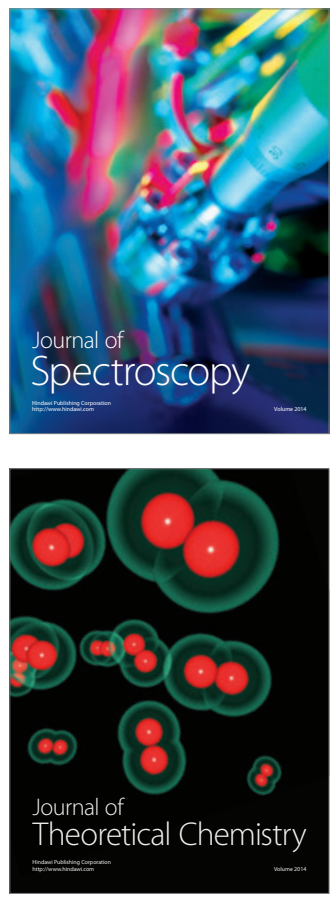
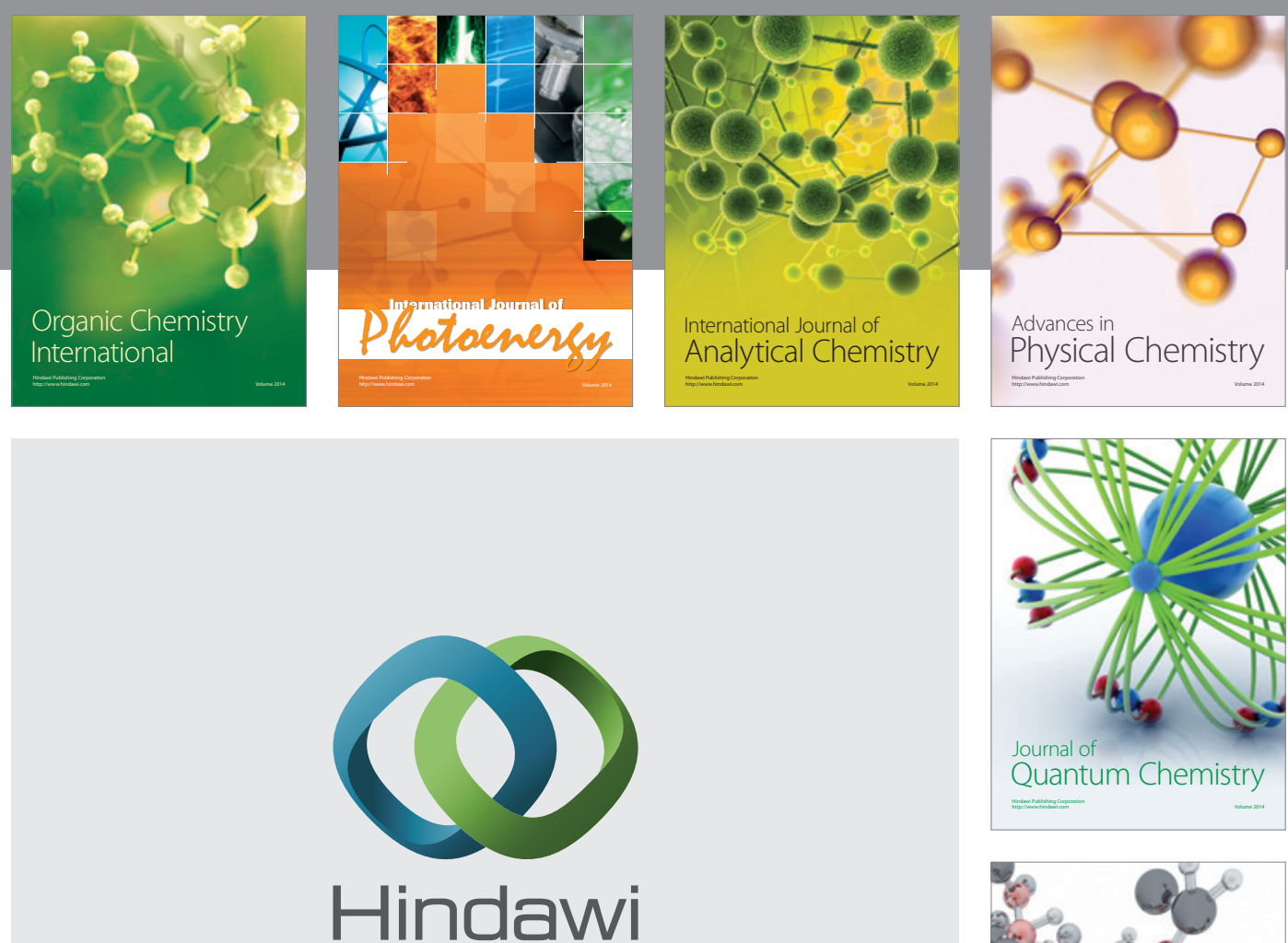

Submit your manuscripts at

http://www.hindawi.com

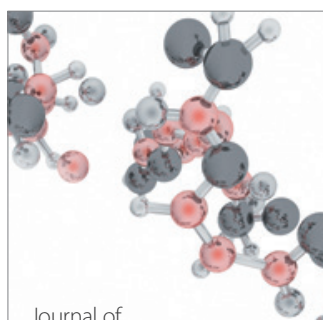

Analytical Methods

in Chemistry

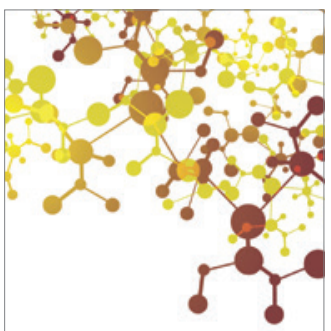

Journal of

Applied Chemistry

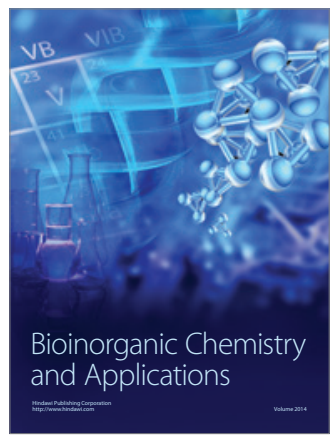

Inorganic Chemistry
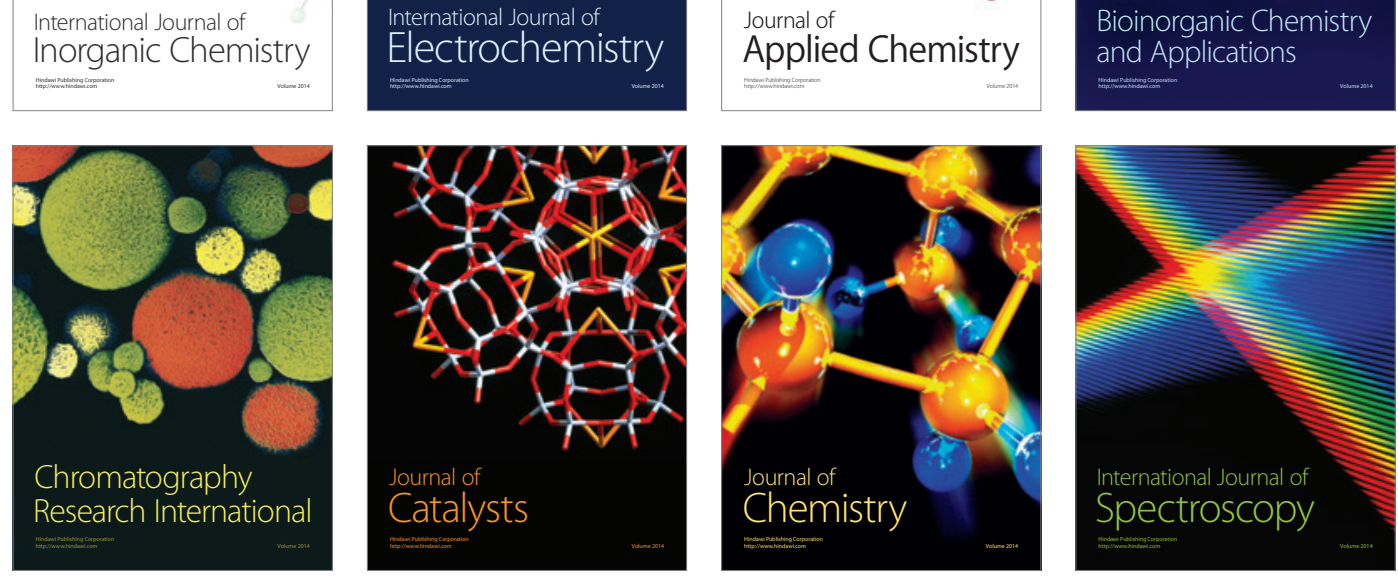